\title{
Influencia del modelo biomédico en la cultura política ecuatoriana
}

\author{
Influence of the biomedical model in Ecuadorian political culture
}

Juan Cuvi **

\section{Introducción}

La idea de la "curación" de la sociedad tiene sus raíces en los tiempos más remotos de la historia conocida. Si la medicina más básica se enfocaba en la necesidad de combatir a la enfermedad como un símbolo del mal que atacaba al organismo biológico, no era difícil extender esta visión hacia el combate a los males que afectaban al organismo social. "Combinada con la idea del progreso, la utopía de la humanidad sana llegó a prevalecer sobre el ideal de modelos concretos y específicos de funcionamiento característicos de cada tribu o polis" (Illich, $\mathrm{s} / \mathrm{f}$ ). No es casual que todas las civilizaciones hayan adaptado un sistema conceptual médico al discurso político, con la finalidad de explicar el funcionamiento de la sociedad y designar sus principales falencias. De este modo, a lo largo de los siglos hemos acumulado y estructurado un conjunto de términos médicos comúnmente aplicados al mundo de la política y de la sociología: crisis, cáncer, lacra, descomposición, contagio, enfermedad, infección, remediación, paliativo, paños de agua tibia,... simbólicamente, la medicina extiende sus dominios al campo de las ciencias sociales.

Aquí nos interesa analizar la influencia del modelo biomédico -modelo hegemónico en nuestra sociedad- en la cultura política de los ecuatorianos. Al ser la salud un elemento básico y determinante en la vida de cualquier grupo humano, además de imprescindible para el funcionamiento adecuado de la sociedad,

\footnotetext{
* Este artículo es una síntesis de la tesis que el autor está elaborando dentro de la maestría en Desarrollo Local de la Universidad Politécnica Salesiana, sede Quito.

** El autor es licenciado en Gestión del Desarrollo Local de la Universidad Politécnica Salesiana, Ecuador. Actualmente está cursando una maestría en Desarrollo Local en esa universidad y es profesor de Teorías del Desarrollo en la sede Cuenca de la UPS.
} 
el enfoque con que se plantea su manejo resulta fundamental para poder entender muchos de los comportamientos, hábitos y creencias de una colectividad, porque las respuestas que se dan al proceso salud/enfermedad no son, desde ningún punto de vista, neutras. El modelo biomédico fue impuesto desde una matriz eurocéntrica de colonización, tanto en lo cultural como en lo económico. Por lo mismo, ha provocado distorsiones y contradicciones históricas en la construcción del ethos nacional.

La tesis sobre las concepciones y prácticas médicas como determinantes de la cultura política de un pueblo no ha sido planteada ni tratada con la amplitud que amerita. Muy al contrario, existe la tendencia a considerarlas como un reflejo de la esfera económica de la sociedad. Es decir, lo que el marxismo categoriza como un elemento de la superestructura político-ideológica. Desde esta perspectiva, el modelo biomédico no sería más que un instrumento para la reproducción de una formación económico-social específica.

Pero los rasgos que caracterizan la modelo biomédico tienen demasiadas coincidencias con las costumbres y valores dominantes en nuestra sociedad: individualismo, machismo, racismo, clasismo, mercantilismo, fragmentación, etc. Por eso resulta pertinente analizar hasta qué punto las concepciones y prácticas que sostienen al modelo biomédico constituyen un factor relevante en la construcción de referentes políticos y, por consiguiente, de comportamientos relacionados con el ejercicio o el no-ejercicio del poder. Si la profundización de la democracia está en relación directa con la socialización del poder, todas las formas y mecanismos mediante los cuales ese poder puede ser escamoteado requieren ser develados y confrontados.

Son múltiples las entradas para entender las formas en que una estructura de poder se reproduce, se consolida y se sostiene. El rol de la biomedicina ha sido tomado en cuenta desde la instrumentalización de un dispositivo burocrático o desde la implantación de un discurso académico; es decir, desde la administración pública y la institucionalización de los servicios, o desde la supremacía epistemológica. Pero en ningún momento ha sido analizado como un factor autónomo de poder que apuntala todo sistema político basado en la dominación.

Es importante señalar que la literatura con que se cuenta para las formulaciones teóricas respecto de la relación entre medicina y política es escasa y extremadamente tangencial (tal vez por ello también es paradigmática): Michael Foucault, Ivan Illich, Carlos E. Menéndez. 


\section{Problematización del tema}

La relación del ser humano con la enfermedad tiene una trascendencia y un dramatismo que superan a los de cualquier otro factor de carácter natural, social, político o económico. La enfermedad (sea esta física, mental o emocional) es el único enemigo interno del ser humano. No importa si su origen es externo; lo fundamental es que, cuando se manifiesta, lo hace desde nuestra interioridad corporal, psíquica o afectiva. La guerra, el desempleo, las catástrofes naturales o la delincuencia son amenazas que efectivamente pueden ser fatales, pero ninguna opera como la enfermedad. Esta es la única que expresa el conflicto entre la vida y la muerte desde nuestra intimidad más profunda.

La medicina no solo interviene en el subconsciente de la persona; también lo hace sobre el instinto de supervivencia. Una persona sabe que puede renunciar a la religión o a la educación sin poner en riesgo su vida; pero no puede asumir la misma posición respecto de la medicina. Es por ello que los mensajes que provienen desde la medicina tienen posibilidades infinitamente mayores de ser incorporados al sistema de valores de un individuo o de un grupo social. Cualquier persona está dispuesta a procesar el pronóstico del profesor de que si no estudia será un fracasado; sabe que existen innumerables casos que demuestran lo contrario. También puede lidiar con la admonición del sacerdote de que si no cumple con los preceptos religiosos irá al infierno; esta admonición tiene poco efecto inclusive entre los creyentes, que cada día alimentan mayores dudas sobre la existencia del averno. Pero una advertencia del médico es categórica, inaplazable y sobre todo puede ser fatal. Lo reafirmamos cada vez que conocemos de un caso que ha terminado en la muerte del enfermo.

Por eso los seres humanos y las sociedades desarrollamos una relación muy especial y particular con el mundo de la medicina. Y pese a que no mantiene la frecuencia de aquella relación que tenemos con el mundo del trabajo - por citar un ejemplo paradigmático-, no por ello deja de ser una relación crucial. Además, se trata de una relación que establecemos desde antes de nuestra existencia oficial y que perdura hasta la muerte.

La medicina constituye un mundo de representaciones y símbolos que actúa en forma simultánea sobre nuestra exterioridad e interioridad. Nos resuelve necesidades prácticas y puntuales al mismo tiempo que nos transmite valores y cosmovisiones. Al obligarnos a depositar en sus manos algo tan preciado como 
nuestro cuerpo y nuestra salud, sus dispositivos tienen la capacidad de moldearnos con mayor eficacia que otras disciplinas.

Pero esta relación tan estrecha y reincidente es por lo general interpretada desde un punto de vista únicamente instrumental: la medicina sirve o no sirve, cura o mata, alivia el bolsillo o empobrece. Su función social pareciera depender de la eficacia de sus procedimientos. En su calidad de "ciencia que cura las dolencia humanas", la medicina inclusive ha logrado traspasar el rango de neutralidad epistemológica que pretenden las ciencias, para ubicarse en forma casi inamovible en el extremo positivo. Esto facilita que todo mensaje que venga incluido en el tratamiento médico tenga mayores posibilidades de incorporarse o de permear nuestro sistema de representaciones y valores.

El conocimiento médico, su léxico, sus diferentes interpretaciones y explicaciones sobre la realidad ambiental, social e individual, sus prácticas, etc. mantienen una presencia constante y rutinaria en la vida de todas las sociedades. Como lo precisa Menéndez, el proceso de salud/enfermedad/atención es un fenómeno universal que opera en toda sociedad y conjunto social. Los episodios patológicos forman parte de los procesos sociales donde se construye colectivamente la subjetividad, y el sujeto, desde su nacimiento, se constituye como tal -en buena medida- a través de este proceso. Inclusive en sociedades con mejores estándares de salud este proceso domina la vida cotidiana, sobre todo por las estrategias y creencias orientadas a potenciar la salud y demorar el envejecimiento (Menéndez, 2002: 309-310).

La mayor dificultad para el análisis radica en la supuesta neutralidad que asume el discurso biomédico. Pero detrás de este discurso opera una lógica de poder que ha sido ampliamente documentada por varios autores. ${ }^{1}$ Aquí nos interesa el proceso mediante el cual esa lógica de poder es transmitida y estructurada en la cultura política de la sociedad.

\section{Modelo biomédico, ideología y política}

La posibilidad de que la ciencia médica haya alcanzado espacios y niveles de autonomía dentro de la estructura social se presenta básicamente como una

1 La obra de Foucault es fundamental en este sentido. Para la elaboración de este artículo se han revisado varios textos: L'archéologie du savoir (1969), Los anormales (2011), Seguridad, territorio, población (2011), Defender la sociedad (2010), Nacimiento de la biopolítica (s/f). 
consecuencia del desarrollo capitalista de los últimos dos siglos. Históricamente, el modelo biomédico se instauró en los países industrializados como una necesidad para asegurar la reproducción del trabajo. El vertiginoso avance del capitalismo en Europa y Estados Unidos, sobre todo a partir del siglo XIX, que trajo todas sus secuelas sanitarias derivadas de las pésimas condiciones de vida de los trabajadores, obligó a la intervención del Estado como forma de amortiguamiento de la conflictividad social. Nace entonces la salud pública como estrategia de atención orientada principalmente a ese sector mayoritario de la población. "En sentido último, la salud pública como campo independiente de estudio y de práctica es, en efecto, el intento de la sociedad por controlar el comportamiento de sus miembros, de acuerdo con lo que los grupos dominantes y el sistema de valores imperante definen como el bienestar para la comunidad como un todo" (Landy, 1977: 231). En esta lógica política, cualquier sistema médico, sobre todo en lo que respecta a la salubridad y la epidemiología, debía estar estrechamente conectado con los sistemas locales de organización y control social.

Ya para entonces las élites capitalistas habían entendido la importancia de la salud como elemento de la economía, como factor indispensable para la optimización del proceso productivo y la consolidación del sistema. A inicios del siglo XX se incorporó el término capital humano y de la salud al discurso político-económico del mundo desarrollado (Menéndez, 2005b), confirmando con esto que un nuevo engranaje había sido incorporado a la maquinaria productiva del capitalismo. El siglo XX presenció cómo la medicina (al igual que la comunicación) iba paso a paso alcanzando sitiales estratégicos y predominantes en el funcionamiento de la sociedad, hasta convertirse en un factor de poder. Inclusive autores con una innegable raigambre marxista como Jaime Breilh cuestionan las versiones que presentan a la historia de la ciencia médica como un reflejo mecánico de los procesos estructurales, y sostiene que al interior de una tendencia general de determinación estructural, "siempre queda un margen para aquel proceso acumulativo interno de la ciencia que marca su lógica interior y la continuidad relativa" (Breilh, 2010: 89).

¿Es posible que un elemento de la superestructura político-ideológica del Estado, como es una ciencia basada en la construcción de un cuerpo coherente y sistemático de conocimientos, llegue a tener tal peso que pueda por su propia dinámica determinar la organización y el funcionamiento político de una sociedad? Al calor de lo que ocurre con el fenómeno de la comunicación en red 
en los últimos años, sí es posible plantearse esa hipótesis. De instrumento del poder formal expresado en el control de los medios convencionales, que era la forma clásica como se concibió a la comunicación, esta empieza a actuar como un contrapoder gracias a la horizontalidad de las redes sociales y del Internet.

Es cierto que tanto la comunicación como la medicina han estado $-\mathrm{y}$ en buena medida siguen estando- relacionadas con intereses económicos y políticos muy concretos. Gran parte de su desarrollo y operatividad ha respondido a la lógica general del sistema, cuyos parámetros generalmente son definidos desde las distintas instancias de poder. No se puede desconocer que la medicina es parte integral de un subsistema que involucra a productores de equipos e insumos, a inversionistas y grandes financistas, a burócratas y fuerzas armadas, a laboratorios y corporaciones farmacéuticas. Es decir, a actores de la economía que establecen relaciones sociales de producción muy concretas y que, en tal virtud, actúan en el nivel de la infraestructura socioeconómica del Estado. Es evidente que el modelo biomédico fue paulatinamente construido para darle salida a los intereses, a las visiones y a los conflictos de poder de estos grupos. Pero al igual que ha ocurrido con la comunicación -cuyos hilos de dependencia política, ideológica y cultural formales se han ido poco a poco rompiendo por la irrupción de las redes sociales-, el modelo biomédico actual tiende a reproducir, desde una dinámica epistemológica y una visión del mundo propia -y hasta cierto punto autónoma-, una serie de valores y concepciones que llegan a tener fuerte influencia sobre el comportamiento de una sociedad.

En la relación dialéctica y de mutua determinación entre elementos de la infraestructura socioeconómica y la superestructura político-ideológica del Estado, es posible que la concepción médica hegemónica juegue un rol tanto o más importante que la religión, la educación o el derecho. No podemos descartar que esta influencia se amplíe hacia el diseño de la organización social, a la configuración de las relaciones sociales y a la propia estructura de poder.

En este punto podríamos aplicar la tesis que ensaya Bolívar Echeverría para explicar la relación entre modernidad y capitalismo. Según este autor, la modernidad es una forma histórica de totalización civilizatoria de la vida humana, mientras que el capitalismo es una forma de reproducción de la vida económica del ser humano. "Entre modernidad y capitalismo existen las relaciones que son propias entre una totalización completa e independiente y una parte de ella, dependiente suya, pero en condiciones de imponerle un sesgo especial a su trabajo de totalización" (Echeverría, 2001: 146). Este sesgo sería el predominio de la 
dimensión económica de la vida. Si hacemos una analogía con la relación entre modelo biomédico y sistema político, podríamos hablar de una totalización independiente que se afirma con la imposición del liberalismo como modelo de dominación política de la modernidad, de la cual el modelo biomédico se convierte -particularmente desde finales del siglo XIX-en una parte que le impone un sesgo a esa totalidad que lo contiene, sesgo que se acentúa a medida que el modelo biomédico desarrolla las formas de autonomía, hegemonía y poder que hemos señalado anteriormente. Si a esta proposición añadimos que el liberalismo constituye la principal matriz política de la modernidad, de cuyo seno surgieron otros modelos de dominación como el fascismo, el socialismo real o el populismo, entonces podemos concluir que el modelo biomédico es un elemento con una fuerte influencia en el funcionamiento de los principales sistemas políticos de Occidente desde hace más de un siglo.

Por otro lado, si partimos de la constatación de que en toda sociedad existe una autonomía relativa de la salud en manos de los grupos sociales, podemos deducir que cualquier modelo de salud puede desarrollar mecanismos de autoreproducción, independientemente de los condicionamientos impuestos por la dinámica y los requerimientos del sistema en su conjunto. Esto sería más evidente en el caso del modelo biomédico, tanto por el peso de su influencia en el sistema-mundo capitalista actual como por su increíble adaptabilidad a los cambios tecnológicos y culturales. Podríamos, en este caso, ensayar una pregunta provocadora y hasta cierto punto capciosa: ¿es el modelo biomédico el que en última instancia traza la ruta de los grandes intereses multinacionales de la salud, o son estos los que definen la evolución del modelo?

Es necesario señalar que esta potencialidad superestructural del modelo biomédico interviene más allá del esquema estructural del capitalismo para el que originalmente fue diseñado, pues terminó sirviendo para legitimar cualquier sistema político dominante, sin importar su tendencia ideológica. Como lo menciona Menéndez con gran agudeza, ha sido un modelo de salud que ha legitimado, de manera indistinta, a regímenes liberales, fascistas, socialdemócratas, comunistas o populistas. En otras palabras, ha fortalecido una determinada cultura política a partir de rasgos comunes. El desafío, entonces, es descubrir cuáles son esos rasgos y cuáles las coincidencias que lo han hecho tan funcional. Lo que al menos queda claro es que, como producto de la modernidad, el modelo biomédico se adapta a cualquier expresión cultural, social, política o económica de dicha modernidad. 
Por ello, al ser el socialismo real una manifestación de la modernidad se explicaría que el modelo empate, en muchos aspectos, con un sistema como el cubano. Lo que puede variar es el carácter privado de su finalidad en un régimen liberal, lo cual permite una acumulación de capital en pocas manos (empresas, profesionales, burócratas); pero el modelo se mantiene en un régimen socioeconómico y político distinto, inclusive con rasgos como la elitización de los profesionales médicos, aspecto este que en una sociedad socialista tiene repercusiones más chocantes porque pone en evidencia prebendas y desigualdades sociales.

\section{Características del modelo biomédico}

Para entender estas similitudes funcionales del modelo biomédico en regímenes tan distintos es necesario identificar sus características más relevantes. Eduardo Menéndez (Menéndez, 1988; Menéndez, 2005b) propone las siguientes: biologismo, asociabilidad, ahistoricidad, aculturalismo, autoritarismo mercantilismo/ salud/enfermedad como mercancía, individualismo, eficacia pragmática, profesionalización formalizada, legitimación jurídica, relación médicopaciente asimétrica y subordinada/exclusión del saber del paciente, identificación ideológica con la racionalidad científica, tendencia a la medicalización de los problemas, tendencia a la escisión entre teoría y práctica, tendencias inductivas al consumo médico.

A estas características habría que añadir otras que han sido consignadas en publicaciones anónimas o que pueden obtenerse de fuentes informales y de la propia observación.

- Fragmentación. Esta visión se aplica tanto al organismo como a la integralidad del proceso salud/enfermedad. En el primer caso, el cuerpo humano es visto como una sumatoria de partes orgánicas que pueden ser manejadas en sus respectivos compartimentos. Esta fragmentación incluye a los elementos psicológicos y emocionales. En el segundo caso existe una evidente separación de los factores sociales, ambientales, laborales, culturales y económicos que actúan sobre la salud y la enfermedad.

- Mecanización. Al cuerpo humano se lo concibe como una máquina, a la enfermedad como un desperfecto y al médico como un mecánico que la repara. Esta característica está directamente relacionada con la anterior: 
hay partes que pueden ser "reparadas o respuestas" sin incluir ni afectar a la totalidad del sistema vital.

- Racionalidad técnica. Todo fenómeno debe ser medido, probado, demostrado o verificado a través de instrumentos técnicos. No existe lugar para la incertidumbre, y se deja de lado toda especulación. La intuición del médico cae en el plano de la superchería. El positivismo se impone sobre el empirismo así como el instrumento se impone sobre la iniciativa humana.

- Asimetría. A la relación jerárquica médico-paciente hay que añadirle la relación servicio-demanda. El usuario siempre está a merced del funcionamiento del sistema de salud, lo cual depende de los niveles de eficiencia, calidad, calidez, financiamiento, solvencia, disponibilidad, etc. con que este opera. Una huelga de los servicios de salud, por ejemplo, afecta el derecho de acceso de los usuarios.

- Visión curativa. El propósito es tratar con enfermedades y no con pacientes enfermos. La enfermedad está considerada como aquella dolencia que el médico puede reconocer, diagnosticar, clasificar y curar al margen de las percepciones, creencias y sugerencias del paciente.

- Andamiaje teórico reduccionista. Las explicaciones sobre el proceso salud/enfermedad se enmarcan en tres concepciones de corte biologista/ positivista: la anatomía clínica, que atribuye el origen de las enfermedades a una lesión; la fisiopatológica, que la atribuye a la alteración de los procesos orgánicos; y la etiológica, que la atribuye a causas externas.

- Principio de dominación epistemológica. El modelo biomédico se sustenta en una relación de superioridad del conocimiento racional-científico sobre cualquier otra forma de conocimiento o saber; subordina, neutraliza, descalifica o simplemente elimina los sistemas y/o prácticas médicas diferentes. En este sentido, responde a una esencia cultural colonialista. Inclusive al interior de la propia estructura teórica del modelo biomédico se establecen relaciones de superioridad/inferioridad entre conocimiento especializado y conocimiento general.

- Estructura corporativa/burocrática. Las relaciones de poder están basadas en la primacía de las instituciones y de los cuerpos de profesionales (médicos, funcionarios públicos, enfermeras, trabajadores de la salud, técnicos, expertos) sobre los usuarios y la población en general. Toda expresión de informalidad es desvalorizada o queda excluida del modelo. 
- Lógica utilitaria. Apunta a resolver necesidades puntuales de forma inmediata y práctica. La medicina debe reaccionar ante los problemas de salud más epidérmicos, no ante los problemas de fondo. Actúa como una ciencia de los fenómenos y no de las estructuras.

A simple vista, la mayoría de características señaladas poseen una raigambre incuestionablemente liberal, lo cual resulta por demás obvio, puesto que como ya se dijo, el modelo biomédico fue desarrollado y adaptado a las necesidades del capitalismo. Lo que sorprende es que haya sido acogido por países con sistemas económicos socialistas, para cuyo propósito se le aplicaron algunos retoques. Al final, la pretensión de universalidad que acompañó a la estructuración de la ciencia médica en forma de modelo, allá por los siglos XVIII y XIX, terminó siendo una realidad a pesar de las profundas e irreconciliables contradicciones que se dieron en la aplicación de modelos políticos y económicos en distintas partes del mundo. En este punto podríamos hacer una breve analogía con la imposición del modelo industrial en Europa. Los criterios de eficacia, rendimiento, disciplina laboral, estímulos productivos, emulación, etc., propios de la industrialización capitalista, fueron adecuados al sistema de producción "socialista" de la URSS desde sus inicios, bajo la modalidad leninista del centralismo democrático, que no es otra cosa que una versión taylorista de la producción basada en la mayor centralidad posible del gerente.

\section{Imposición del modelo biomédico}

El modelo biomédico fue una construcción de la modernidad capitalista ante la necesidad de asegurar la reproducción de la fuerza de trabajo, optimizar los procesos productivos y reducir las amenazas epidemiológicas que también podían alcanzar a las élites. Es decir, se trató de una construcción teórico-instrumental basada en la existencia y justificación de diferencias y jerarquías sociales. Su propósito final fue siempre el apuntalamiento del sistema dominante, de los mecanismos de dominación y de la estructura de clases. Algunas de sus principales características, como por ejemplo su ahistoricidad, su fragmentación, su asociabilidad, su aculturalismo o su reduccionismo teórico contribuyen a reforzar una concepción estática de la Historia y de la sociedad. Es en esencia una propuesta conservadora que rechaza el carácter integral y dinámico de todo 
proceso social. En cierta forma es un modelo antidialéctico, estructurado sobre principios "duros" que difícilmente admiten su propio cuestionamiento. Como lo señala Menéndez, para el modelo biomédico "la enfermedad evoluciona pero no tiene historia" (Menéndez, 1988). Illich también insiste en esta condición cuando afirma:

Toda enfermedad es una realidad creada socialmente. Su significado y la reacción que evoca tienen una historia. El estudio de esa historia puede permitirnos entender el grado en el que somos prisioneros de la ideología médica en que fuimos formados (Illich, s/f).

A la necesidad de dar respuestas a las exigencias estructurales del sistema capitalista se suman las exigencias de carácter ideológico (una visión particular del mundo y de la vida) y político (operativizar mecanismos de control). En efecto, el proceso salud/enfermedad tiene profundas connotaciones políticoideológicas, que el modelo biomédico tiende a encubrir desde una racionalidad técnica. Su discurso positivista y su práctica instrumental buscan opacar las contradicciones sociales y, por ende, las diferencias de poder inherentes al proceso salud/enfermedad. En tal sentido, el modelo biomédico encarna un discurso eminentemente político o, más propiamente, una disimulación del discurso político oficial. A diferencia de lo que ocurre con la religión, la educación o la comunicación, cuya función y finalidad evidentes y no disimuladas son la transmisión de mensajes, valores, creencias, conductas, ideas, visiones, normas, etc., la medicina se presenta como una disciplina neutra, promotora de un único propósito superior e imposible de ser puesto en duda: curar.

Esta aparente neutralidad, sumada a la eficacia instrumental, se tradujo en una superioridad epistémica difícil de cuestionar. El modelo biomédico terminó imponiéndose principalmente a través de la exclusión ideológica de los modelos alternativos, y secundariamente a través de la exclusión técnica y profesional. Al identificarse con los estratos dominantes de la sociedad, puede descalificar las prácticas y saberes identificados con los estratos dominados. Se impuso primero gracias a la práctica médica privada, y luego pública. Esta última es la que posibilitó "vender" el modelo a las clases explotadas.

En este largo y sostenido proceso de imposición del modelo biomédico, como resultado del avance y expansión del capitalismo, el Estado liberal se empeñó en entronizar a los profesionales médicos en lugares predominantes de la estructura de clases, con lo cual le aseguró a la práctica médica legitimación 
cultural, técnica, política, social y académica. El estamento médico empezó a tomar iniciativas públicas que no pueden ser consideradas simples apéndices de los intereses de las grandes corporaciones de la salud, como ocurre y se ha denunciado a menudo. Detrás de muchas de estas decisiones médicas actúa el deseo de ejercer poder, y la intención de reforzar aquellos referentes simbólicos que permitan legitimar aún más el modelo médico hegemónico. En cierta forma, se trata de la reproducción de esta esfera de la superestructura. Para ello, la "clase médica" utiliza la potestad que le ha conferido la sociedad, y sobre todo el Estado, para pontificar sobre los problemas de salud/enfermedad, lo cual le permite, entre otras cosas, aplicar criterios nosológicos a las conductas individuales o a las manifestaciones sociales consideradas anormales, como la locura, el alcoholismo o las adicciones.

Esta potestad clasificatoria puede extenderse también a las amenazas de otra índole que enfrenta la sociedad, y que provocan alarma y miedo en la población. Los riesgos, la incertidumbre y la inseguridad empiezan a ser vistos como fenómenos incontrolables, manejables únicamente por expertos, entre ellos epidemiólogos y psicólogos. Estas amenazas, que pueden tener características económicas, ambientales, sanitarias, políticas o culturales, se relacionan directa o indirectamente con el proceso salud/enfermedad, porque provocan desequilibrios en nuestra condición emocional, física, mental, laboral, familiar, etc. Nos afectan como individuos y como cuerpo social. Desde la óptica del poder imperial, por ejemplo, el islamismo llega a ser visto como una "enfermedad religiosa-cultural" que debe ser combatida con una terapia contundente y extrema como la guerra.

Nos topamos aquí con una práctica que nos retrotrae, en términos de la Historia moderna, a los momentos más aterradores y sanguinarios de la nouvelle République francesa. En el verano de 1793, Barère de Vieuzac pidió desde su tribuna que toda la fuerza militar cayera sobre los rebeldes católicos de la Vendée. "En las heridas gangrenosas la medicina aplica el hierro y el fuego... La medicina política debe emplear los mismos remedios", clamó, y su pedido se hizo eco con una masacre que exterminó a toda una población civil. "Siguiendo vuestras órdenes, he aplastado a los niños bajo los cascos de los caballos y he masacrado a las mujeres, que ya no darán a luz más bandidos. No he hecho prisioneros. Lo he aniquilado todo", informaba el general Westermann a la Convención el 23 de diciembre de ese mismo año (Martínez Mesanza, s/r). La cirugía política llevada a los extremos del horror, la medicina más agresiva 
al servicio del poder, el tumor de la rebelión extirpado del cuerpo social para mantener con vida al sistema.

No constituye ninguna casualidad que ese discurso haya surgido, y se haya impuesto, precisamente durante la efervescencia revolucionaria de la Francia de finales del siglo XVIII. Era el momento en que la medicina debía recoger y estructurar para sus dominios los aportes de la razón instrumental, de la invención industrial y de la técnica. Era el momento de implantación de la visión biomédica, cuyas concepciones podían extenderse al plano social. Pero el modelo biomédico todavía tendría que recorrer un largo trecho en calidad de simple instrumento del poder político, de componente subordinado dentro de la estructura del Estado.

Una de sus funciones políticas más significativas ha sido la clasificación de las enfermedades y riesgos para la salud desde una orientación ideológica, en una especie de entramado técnico para la generación de miedos en la sociedad. Alerta sobre la mayor o menor peligrosidad de una enfermedad y, con ello, manipula la sensación de inseguridad en la población. No solo que magnifica los aspectos negativos de una enfermedad, sino que presagia catástrofes sanitarias que deben ser manejadas por los sectores hegemónicos de la sociedad, es decir, por los grupos de poder (Menéndez, 2008: 21-22). En tal virtud, las decisiones médicas actúan como un mecanismo efectivo de dominación política.

\section{Discurso biomédico y cultura política}

La extrema medicalización de la salud ha convertido a la medicina en un insumo regular en nuestras vidas. Es parte de nuestra cotidianidad. En el mundo actual, el sujeto entra en contacto directo e intensivo con el modelo biomédico incluso antes de nacer y, eventualmente, antes de ser concebido, como ocurre con la inseminación artificial. Tanto el proceso salud/enfermedad como las particularidades del modelo de atención terminan dominando la vida cotidiana del individuo.

En sociedades menos cohesionadas, y con una institucionalidad frágil como la nuestra, el dominio del modelo biomédico puede ser desordenado y disperso, pero indudablemente existe. En ese sentido, se comporta como un factor determinante en la creación de referentes ideológicos. Más allá de la coexistencia con prácticas médicas y modelos alternativos, se impone una visión dominante que invade la cotidianidad y la conciencia de la gente y que, gracias a la inter- 
vención masiva del Estado, se difunde y copa todos los espacios de la sociedad. "La expansión biomédica sobre los saberes populares constituye uno de los episodios más interesantes de construcción de hegemonía, que refuerza no solo la dominación médica profesional sino que favorece también la dominación política e ideológica de los sectores dirigentes a través del campo específico de la salud" (Menéndez, 2008: 25-26). Cabe resaltar que, en el caso particular de la ciencia médica, esos episodios son hábilmente disimulados tras un andamiaje de prácticas y procedimientos técnicos muy bien montados, difícilmente cuestionables ante la efectividad de sus acciones curativas.

$\mathrm{Si}$, como hemos analizado, el modelo biomédico está condicionado por factores de carácter económico (la necesidad de asegurar la reproducción del trabajo asalariado) e ideológico (la necesidad de imponer una visión de la salud que facilite el control social), puede cumplir una función importante en la consolidación y mantenimiento del sistema político hegemónico de turno. La biomedicina construye símbolos y representaciones que derivan en formas particulares de pensar y, en consecuencia, de actuar políticamente. Desde antes de desarrollar una conciencia básica, es decir desde una edad temprana, los seres humanos establecemos una relación íntima, reiterada y en ciertas ocasiones dramática con una concepción específica sobre la salud y la vida.

Por otro lado, la complejidad del léxico médico nos obliga, desde nuestro primer contacto consciente con un servicio de salud, a seguir las instrucciones sin más preguntas que las indispensables para la ejecución de la orden médica. $\mathrm{Ni}$ siquiera las corrientes teóricas que abogan por una mayor participación del paciente en la consulta posibilitan superar esa condición de inferioridad frente al saber médico. Se refuerza así una cultura jerárquica que actúa en el subconsciente y hasta en el propio instinto, y que luego se pone de manifiesto en nuestra cotidianidad. En cierta forma, los servicios de salud basados en el modelo biomédico pueden ser vistos como una escuela de autoritarismo.

El acto de asistir a la consulta médica constituye un acto social, psicológico, afectivo y cultural que tiene relación dialéctica con nuestra intimidad, creencias y subjetividad. El tipo de medicina al que acudamos puede moldear nuestra visión del mundo y de la vida y, por ende, puede influir en nuestras posturas políticas. Por ejemplo, la idea de que la enfermedad se detecta mediante procedimientos instrumentales puede inculcarnos la idea de que los problemas sociales también deben diagnosticarse mediante técnicas positivas como las estadísticas o las mediciones. Esta inclinación tecnocrática está tan difundida 
que a menudo se utiliza la imagen de la "radiografía" para describir una problemática socioeconómica concreta.

De igual modo, la creencia de que la salud se recupera mediante el uso de recursos técnicos (medicamentos, insumos, aparatos de rehabilitación o procedimientos quirúrgicos) puede inducirnos a pensar que los problemas sociales se resuelven gracias a la utilización de recursos materiales o de medidas drásticas. ${ }^{2}$ Por efecto de esta ecuación simplista la ingeniería civil prevalece sobre la gestión ambiental, la producción sobre los derechos de género, los ingresos sobre la afectividad. La infraestructura física, es decir la obra pública palpable, consolida su cualidad de referente del desarrollo y del bienestar de la gente.

Pese al desarrollo experimentado por algunas ramas de la medicina más sociales, el modelo biomédico sigue manteniendo e impulsando una marcada visión individualista. Como producto de la modernidad capitalista, vio la luz impregnado de una racionalidad liberal avasallante, de una concepción del mundo que se presentó como la panacea para curar las injusticias y desigualdades sociales. A los derechos civiles de los individuos libres debían corresponderles similares derechos médicos en su calidad de pacientes. Es por ello que lo que podríamos denominar como la "medicina de la modernidad" se desarrolló en un ámbito estrictamente privado. Como todas las demás ciencias que tuvieron su impulso a partir de la afirmación global del capitalismo, debía también contribuir a una visión del mundo basada en el laissez faire; es decir, debía asegurar la capacidad de cada individuo para desarrollar sus potencialidades, competir y alcanzar el éxito en medio de una sociedad librada a las fuerzas del mercado. En este contexto era inevitable que la ciencia médica adquiriera connotaciones clasistas, en tanto los mayores referentes del nuevo hombre libre eran empresarios burgueses.

Inclusive el experimento soviético de inicios de la revolución terminó cediendo espacio a los rasgos más destacados del modelo biomédico. Allí se liquidó el poder de los médicos a favor de los curadores tradicionales (feldsher) como un cuestionamiento de clase, pero únicamente en cuanto al componente comercial de la práctica médica pre revolucionaria. "Ninguno de los otros rasgos fue modificado sustancialmente, e incluso en algunos caos se han incrementado

2 Habría que analizar en qué momento de la historia de Occidente se difundió la lobotomía como opción terapéutica para tratar los desórdenes mentales, y cuánta influencia tuvo esta técnica para la aplicación de medidas políticas brutales para extirpar la "locura" social (es decir las acciones contestatarias, revoluciones, actos de resistencia, etcétera.). 
tendencias del MMH [modelo médico hegemónico] que fueron cuestionadas en un inicio" (Menéndez, 1984: 28), como ocurre con las enfermedades mentales y el alcoholismo, que cada vez más se tratan con criterios biologistas.

En nuestra sociedad, ese espíritu liberal del modelo biomédico ha logrado afianzarse aún más debido a la debilidad crónica del Estado, a la ausencia de un verdadero sistema público de salud, a la mayor influencia cultural de los Estados Unidos y a la informalidad institucional. La consecuencia ha sido una sobrevaloración de la medicina privada, que se impone a pesar de las evidencias que lo contradicen. La mitificación de los servicios privados de salud fortalece la faceta comercial de la medicina en desmedro de una propuesta basada en la solidaridad, en la responsabilidad social y personal, en el autocuidado y en el apostolado de la profesión médica. Al quedar sometida a la ley de la oferta y la demanda, donde lo que prima es el valor de cambio de los servicios, la biomedicina aboga por un sistema político que se basa igualmente en el intercambio de intereses antes que en el servicio.

La comercialización de la salud, a su vez, tiene relación directa con el pragmatismo que también caracteriza al modelo biomédico. La respuesta eficaz e inmediata de la intervención médica, orientada a satisfacer la valoración costo/beneficio que exige el usuario, contagia a los demás ámbitos de la vida social, entre ellos el político. Así como los hábitos saludables son sacrificados en aras de la instrumentalización médica -más práctica y menos complicada-, la complejidad política es remplazada por las acciones urgentes y puntuales. Si el cuerpo humano puede ser curado con medidas contundentes e inmediatas como un medicamento o una intervención quirúrgica, también podría serlo el cuerpo social. Sobran entonces la elaboración teórica, la planificación, el debate conceptual, el análisis profundo de los programas de gobierno y la construcción de estrategias.

La especialización del poder reproduce en el campo político una de las características del modelo biomédico. Y pese a que este fenómeno se presenta desde tiempos muy remotos, ${ }^{3}$ es a partir del siglo XX que se convierte en una estrategia de control cultural luego de la atomización del cuerpo humano. El avance técnico-científico de la medicina, y la mayor capacidad de consumo de ciertas capas sociales, potenció el desarrollo de las especialidades. No se puede

3 En el antiguo Egipto ya existían especialidades médicas, a tal punto que el propio Herodoto señaló que tenían un médico para cada enfermedad, así como funciones auxiliares al médico. También entre los Aztecas había especialistas: el médico shamán (ticitl) versado en procedimientos mágicos; el teomiquetzan, experto en heridas y traumatismos de guerra; la tlamatiquiticitl o comadrona. 
atribuir a la medicina la visión fragmentada de la realidad y de la sociedad que prima desde hace algunos siglos en Occidente. Desde una perspectiva epistemológica, la idea de fragmentación de la realidad corresponde al desarrollo de las ciencias naturales a partir del Renacimiento. Pero sí le corresponde a la ciencia médica haber aplicado este principio a su campo prioritario de estudio, es decir, al cuerpo humano. $\mathrm{Y}$ al ser este un elemento consubstancial a la visión que los seres humanos nos hacemos del cosmos y de la existencia, así como un referente de la estructuración de la naturaleza y del funcionamiento de la vida, su fragmentación desde la medicina tiene mayor influencia en nuestro comportamiento que la que podrían tener otras disciplinas.

Por otro lado, el desarrollo tecnológico de la medicina, que ha facilitado la fragmentación del cuerpo humano, da paso ahora a un reduccionismo aún más peligroso: la micro manipulación. El potencial modificatorio de la ingeniería genética induce a creer en la posibilidad de diseñar una sociedad desde la técnica antes que desde la antropología, la política o el ambiente. Si se puede alterar el origen (gen) de una persona, ¿por qué no intervenir sobre la unidad básica de la sociedad -es decir sobre el individuo- para "perfeccionarla" y asignarle a las personas roles y conductas predeterminados?

En cierta forma, la proliferación interminable de especialidades responde a una concepción tecnocrática de la medicina, formulada con el propósito de posibilitar una administración burocrática del sistema de salud. La derivación de casos opera exactamente igual que la tramitología en el sector público, y no tiene otra finalidad que desestimular la acción del individuo en tanto sujeto social.

Al facilitar la burocratización del sistema de salud, el modelo biomédico promueve una cultura de la pasividad y de la resignación que conduce a posiciones político-ideológicas conservadoras desde la sociedad. Como lo señala Menéndez (Menéndez, 2005b) en su análisis sobre el sector salud en nuestra sociedad, este tiene una visión de la población como actor pasivo. Inclusive cuando promueve la participación social aplica criterios verticales, autoritarios y asimétricos, pues tanto la convocatoria como las condiciones de participación son impuestas por la autoridad sanitaria.

4 En 1640, en su obra De Corpore Politico, Thomas Hobbes empieza a desarrollar su idea del cuerpo político como una construcción social artificial, a partir del referente natural del cuerpo humano. Esta idea será profundizada en su célebre Leviatán. A partir de ese momento, las nociones de poder político y salud política empiezan a manejarse como sinónimos hasta bien entrado el siglo XIX (citado por Krakauer, 1991: 244-245). 
La burocracia ha resultado ser el mejor estímulo para el miedo al cambio. El modelo biomédico ha desarrollado sorprendentes mecanismos de reproducción y adaptación para hacer inviable cualquier transformación social. Por ejemplo, su estrategia expansiva, invasiva y hegemónica no solo que subordina a los modelos alternativos, sino que los subsume y les extrae lo que resulta más funcional. Este fenómeno tiene alcances globales: aunque en Occidente están penetrando otras tradiciones médicas académicas, en sus países de origen (Japón, China o India) la biomedicina, al contrario, está expandiéndose y pasando a ser hegemónica. La expresión más notoria de esta conquista es el consumo de medicamentos producidos por la industria farmacéutica (Menéndez, 2005). Podríamos entonces concluir que el modelo biomédico actúa como un exitoso promotor del capitalismo a escala planetaria.

En el caso ecuatoriano es muy fácil percatarse del contenido conservador de las políticas de salud, cuando se revisan los programas de gobierno de los partidos políticos, en los cuales priman las vertientes más retrógradas y convencionales: infraestructura física, equipamiento, dotación de medicamentos y asignación de personal médico especializado. Estas ofertas son entendibles desde una óptica estrictamente electoral: sería un suicidio político ofrecer algo distinto de lo que la población imagina. Lo grave ocurre cuando observamos que esas promesas electorales se convierten en ejecutorias gubernamentales, con lo cual se confirma que se trata de hondas convicciones más que de simples estratagemas electorales.

La burocratización de los procesos, en general, suelen ser causa y efecto del funcionamiento autoritario de cualquier espacio social. Desde la mitificación del saber médico, iniciada con la profesionalización de la medicina, hasta la institucionalización de los sistemas públicos de salud en el siglo XX, el modelo biomédico experimentó un lento pero sistemático proceso de jerarquización, basado tanto en la superioridad del conocimiento como en la autoridad política. Médicos, tecnócratas y funcionarios públicos quedaron encargados de imponer condiciones, medidas, estrategias y políticas de salud desde una óptica de responsabilidad estatal sobre las necesidades y condiciones de salud de la colectividad. La prevención y la cura de las enfermedades de la población se convirtieron en una obligación política, que justificó la imposición desde el poder (público y privado) de medidas y acciones concretas. Fue la consolidación de lo que Foucault designó como biopolítica, un concepto acuñado por él para 
analizar las formas y mecanismos, con los cuales el poder ejerce control sobre la vida de los individuos, particularmente en la modernidad ${ }^{5}$.

El modelo biomédico, entonces, estaría contribuyendo de manera decisiva al diseño de una institucionalidad autoritaria, cuyo principal cometido es el control social, cultural y político de la sociedad. Y esta finalidad no hace distinciones entre sistemas políticos ni económicos, puesto que es aplicado con gran eficacia en regímenes socialistas, liberales, populistas o fascistas. Aunque según Menéndez (Menéndez, 1998: 58-59) todo sistema médico hace referencia a un sistema cultural del que forma parte y es expresión, cabe preguntarse si, en las actuales condiciones de la globalización, el modelo biomédico no actúa más bien como un "constructor" autónomo de instituciones (culturales, económicas y políticas). Estaríamos refiriéndonos aquí a un elemento de la superestructura que, siendo resultado de las necesidades e intereses de la dinámica socioeconómica de la sociedad capitalista, termina estableciendo una fuerte independencia respecto de esas condiciones materiales que en principio determinaron su existencia. El modelo biomédico, para efecto de lo señalado, no estaría actuando únicamente como un retroalimentador teórico e ideológico del mundo real de la medicina, sino como un definidor de otros ámbitos de la vida social, como sería el de la cultura política.

Ahora bien, estas inclinaciones autoritarias y burocráticas del modelo biomédico no pueden estar desligadas de una tendencia a la centralización de los sistemas de salud, y a la concentración monopólica de los servicios públicos y privados. Del dominio de la biomedicina como profesión liberal hemos transitado a una etapa donde se impone la medicina corporativa (ver Menéndez, 2005b). Es precisamente este proceso, el que ha hecho posible una cada vez mayor uniformización de visiones, procedimientos y prácticas médicas, sobre todo en aquellas sociedades donde la fragmentación social y cultural ha permitido la pervivencia de una importante diversidad de saberes y/o modelos médicos.

El punto que se refiere a la uniformización del discurso médico es particularmente preocupante por los efectos adversos que tiene sobre la cohesión social, de manera especial en las comunidades más pobres y en las zonas rurales e indígenas. El desmantelamiento o la desvalorización sistemáticos de las prácticas

5 Los conceptos biopoder y biopolítica constituyen uno de los pilares del pensamiento de Michael Foucault, y están presenten en muchas de sus obras y cursos, así como en una amplia lista de entrevistas concedidas a innumerables medios. 
y saberes médicos alternativos atentan contra las identidades comunitarias y, por lo mismo, minan la capacidad de los pueblos para resistir y dar respuesta a la ofensiva de la globalización. Leslie señala que la profesionalización de lo que él denomina medicina cosmopolita, que ha experimentado un rápido progreso en el siglo XX, constituye un esfuerzo por reducir el grado y controlar la naturaleza del pluralismo médico. Esto implica, entre otros propósitos, la eliminación o la restricción de todas las demás formas de práctica médica (Leslie, 1977: 512-513).

No olvidemos que la eficacia de esta ofensiva radica en que apunta a un componente íntimo e imprescindible de la existencia social e individual. Es decir que esta forma específica de destrucción de identidades es aún más devastadora, porque no solo amenaza la supervivencia de los grupos sociales en tanto pueblos sino en tanto especies. No se refiere a la destrucción de formas de trabajo o de producción, de creencias religiosas, de hábitos de consumo y, en general, de patrones culturales; estamos hablando del desmantelamiento de formas concretas de control sobre el cuerpo humano. Al renunciar a los instrumentos ancestrales de manejo del proceso de salud/enfermedad, las comunidades están también renunciando a un proyecto de vida soberano y, por consiguiente, a un proyecto político independiente de la dinámica política dominante. La carga simbólica que conlleva todo proceso de dominación estaría actuando, en este caso, sobre un elemento fundamental para los dominados: el poder sobre la vida misma. Pero no un poder externo y evidente por su brutalidad, sus excesos o su arbitrariedad, como sería la represión o la aplicación de la pena de muerte, sino un poder subrepticio, sutil, "bondadoso" y completamente legitimado.

La promoción de las diferenciaciones sociales, que está en la naturaleza del modelo biomédico, es preocupante porque conserva demasiado tiempo de vigencia y de aplicación efectiva. Y es que la biomedicina tiene marcas de origen tremendamente clasistas, como por ejemplo aprender la clínica en los cuerpos o en los cadáveres de personas pobres y marginales, práctica que termina configurando la estructura ideológica y psicológica del médico. En el caso de los países colonizados, a este clasismo hay que añadirle un componente racista que perdura hasta nuestros días, y que también se aplica en las sociedades industrializadas con sus respectivas poblaciones o etnias marginadas.

Este último punto se inscribe dentro de una característica más abarcadora del modelo biomédico: su condición discriminatoria (por pertenencia de clase, etnia o género). El conocimiento médico como "saber experto" define lo normal y lo patológico inclusive en un sentido social y cultural; desde esa lógica, 
puede asignar roles a las mujeres desde una justificación médica o biológica. Un ejemplo de lo antedicho es que hoy las mujeres siguen refiriéndose a su estado menstrual como "estar enfermas", lo cual, en esencia, significa admitir cierto grado de incapacidad o limitación para desarrollar sus actividades con absoluta normalidad.

En un interesante artículo sobre la producción de sentidos y representaciones alrededor de un elemento tan estrechamente relacionado con la medicina como es el dolor, Rosario Otegui sugiere develar algunos de los instrumentos políticos utilizados desde el poder para reproducir determinadas relaciones de dominación (Otegui, 2000). La idea de resistencia y tolerancia frente al dolor vinculada con una forma concreta de socialización por géneros refuerza la división de roles entre varones y mujeres, y construye una masculinidad anclada en la falsa premisa de que "ellos son más fuertes por naturaleza". Esta premisa supuestamente tiene fundamentos en la biología, y se presenta como incuestionable debido a que el modelo biomédico ha establecido una ruptura entre lo biológico como inmanente y lo cultural como relativo.

Esta diferenciación por géneros tiene su correlato en la plano socioeconómico, al reproducir esta escala de diferenciación entre clases sociales y etnias. Según esta concepción biologista del dolor, los sectores subalternos y dominados, así como los grupos étnicos periféricos, estarían en condiciones "naturales" para soportar el sufrimiento, lo cual los vuelve más aptos para afrontar condiciones de vida desfavorables (pobreza, violencia y marginalidad). Demás está decir la justificación de la explotación social que subyace en este argumento.

Otro elemento que caracteriza al modelo biomédico es la objetivación del proceso salud/enfermedad. Este punto tiene que ver tanto con la racionalidad técnica del modelo como con su eficacia pragmática. La instrumentalización de la acción médica anula al sujeto, ya sea en su calidad de médico o de paciente (y en el caso de este último aún más). La cada vez mayor tecnificación de la formación de los profesionales médicos provoca que se concentre la atención en el signo y se excluya al síntoma (Menéndez, 2000). Se cosifica a la enfermedad incluso para apartarla del propio paciente. No solo se reduce el criterio y la iniciativa clínica del médico, sino que se desecha por completo la opinión, los sentimientos, las sensaciones y los saberes del paciente. Dicho de otro modo, se sacrifica la palabra. El factor humano queda sometido a la supuesta infalibilidad y precisión de los equipos e instrumentos, cada vez más sofisticados, meticulosos y especializados. 
Esta subordinación del sujeto al objeto opera en el campo de la política a través de la supremacía tecnocrática. Se atribuye al técnico o al experto mejores capacidades que el común de la gente para definir un problema social y sus eventuales soluciones desde una mirada "objetiva". No solo que la visión y las opiniones de la población son minimizadas, sino que en muchos casos son tachadas de alienadas, insuficientes, no fundamentadas o simplemente antitécnicas. Mediante este mecanismo de jerarquización tecnocrática, el modelo político se encarga de anular la participación social.

Esta particularidad del modelo biomédico está directamente relacionada con la idea de mecanización que predomina en el proceso curativo biomédico, y que traslada a la vida política la creencia en la causalidad elemental. Así como la intervención terapéutica de un objeto - v.g. un medicamento- tiene la virtud de curar en forma directa y automática una patología, la construcción de infraestructura debe tener virtudes similares de cara a las "enfermedades" sociales. En nuestra sociedad, el encadenamiento causa-efecto de la obra física ha tenido efectos devastadores, de manera particular en aspectos ambientales y culturales. Se construyen carreteras bajo la suposición de que ellas, por sí solas, acelerarán el aparato productivo, y esto, a su vez, beneficiará a la economía del conjunto del país; se construyen centrales hidroeléctricas bajo el supuesto de que la energía eléctrica, por sí sola, asegurará el mejoramiento de las condiciones de vida de la gente. La mecanización de la vida constituye uno de los principales engranajes de esa incontenible maquinaria expansiva que es el capitalismo. A la fetichización de ciertos recursos médicos corresponde una fetichización de la obra física; a ambos se les confiere cualidades casi milagrosas de resolver problemas, en el un caso individuales y en el otro colectivos.

La asimetría de saberes y de autoridad que cultiva el modelo médico tiene una evidente correlación con el mesianismo que caracteriza al populismo y que establece un increíble paralelismo entre la relación político-ciudadano y la relación médico-paciente. Según Bustamante, el ethos dominante en la política prescinde de la noción de "racionalidad", tal como se lo entiende en la modernidad, y se inclina a favor del montaje escénico, de la "representación" de las relaciones sociales, de la coreografía política armada desde el poder (Bustamante, 2003: 351). En nuestra formalidad democrática, el funcionario público debe demostrarle al ciudadano que él conoce y sabe interpretar la naturaleza del mandato encargado; es quien "revela" la voluntad potencial del ciudadano y, en esa intermediación, se presenta como su más adecuado intérprete (Bustamante, 
2003: 354). En el terreno de la medicina ocurre exactamente lo mismo entre quien posee el saber y la capacidad y quienes acuden a él para resolver un estado patológico. En la práctica, y muchas veces sin proponérselo, el médico tiene la capacidad no solo de "revelar" el padecimiento del paciente, sino de interpretar su deseo de sanación y disponer las medidas terapéuticas correspondientes. Es él, en lo fundamental, quien encuentra o posee la solución al problema.

Al igual que el discurso médico, el discurso político ingresa en los dominios de la religiosidad. Se vuelve una liturgia, un ejercicio de representaciones $\mathrm{y}$ ritos que propicia un estado emocional favorable al convencimiento. Es un discurso sobre lo adecuado, no sobre lo verdadero. El ciudadano debe confiar en la palabra del político tal como el paciente confía en la palabra del médico. El político actúa como sacerdote de la sociedad, tanto como el médico lo hace con el cuerpo. A la dualidad sacerdote-médico señalada por Foucault como heredera, a partir de la Revolución Francesa, de las dos misiones fundamentales de la Iglesia: curar almas y cuerpos (Foucault, 2006: 57), nosotros le añadimos un tercer ingrediente: el político como "sanador" de la sociedad. De este modo completaríamos uno de los sueños más preciados del iluminismo, que aún ahora, dos siglos después de haber sido diseñado, no deja de fascinarnos: la medicina como acto político, la curación del cuerpo social como palíndromo de la curación del cuerpo biológico. Es, como lo registra el mismo Foucault, la exaltación del discurso racionalista consagrado en los albores revolucionarios de fines del siglo XVIII: "La primera tarea del médico es, por consiguiente, política: la lucha contra la enfermedad debe comenzar por una guerra contra los malos gobiernos: el hombre no estará total y definitivamente curado más que si primeramente es liberado (...). Si sabe ser políticamente eficaz, la medicina no será ya médicamente indispensable" (Foucault, 2006: 59).

Pero a diferencia del ideal inspirado por los fervorosos revolucionarios franceses, donde el nuevo Estado tenía la responsabilidad de asumir la titánica tarea de curar a la sociedad, en los regímenes populistas esa misión queda encomendada al caudillo de turno y sus cualidades excepcionales, sobrehumanas. En tal circunstancia es imposible evadir una práctica descaradamente demagógica. Así como el ejercicio de la biomedicina no puede substraerse a su promesa de curación, el político populista hace de la promesa su arma de batalla predilecta. En ambos casos se omite una respuesta conjunta y colectiva al problema. El individuo, ya sea en su condición de ciudadano como de paciente, no accede al nivel de las decisiones, por más responsabilidad que asuma en la realización 
de determinadas acciones. El funcionamiento del sistema político ecuatoriano termina atrapado en la contradicción entre lo que se proclama y lo que se hace, entre la promesa que entusiasma y el incumplimiento que frustra. El doble discurso político tiene su correlato en el doble discurso biomédico: la nobleza de su misión (curar y salvar vidas humanas), proclamada con tanta solemnidad, dista mucho de una práctica médica orientada principalmente al lucro.

\section{Bibliografía}

BUSTAMANTE, Fernando

2003 “Cultura política y ciudadana en el Ecuador”, en Felipe BurBANo DE LARA (compilador), Antología: Democracia, gobernabilidad y cultura política.

CUVI, Juan Quito: FLACSO.

2010 La enfermedad silenciosa. Una mirada social a la automedicación en el Ecuador. Quito: Corporación Acción Vital.

FOUCAULT, Michel

2006 El nacimiento de la clínica. Una arqueología de la mirada médica. México: Siglo XXI editores.

2011 Los anormales. Buenos Aires: Fondo de Cultura Económica.

2011 Seguridad, territorio, población. Buenos Aires: Fondo de Cultura Económica.

2010 Defender la sociedad. Buenos Aires: Fondo de Cultura Económica.

1969 L'archéologie du savoir. Édition Gallimard.

$\mathrm{s} / \mathrm{f} \quad$ Nacimiento de la biopolítica. Buenos Aires: Fondo de Cultura Económica.

LLICH, Iván

s/f Némesis médica. Joaquín Moritz editores, versión electrónica.

KRAKAUER, Erik

1992 "On Medicine and Politics", en: The Yale Journal of Biology and Medicine, No. 65, pp. 243-249.

LANDY, David (ed.)

1977 Culture, Disease and Healing. Studies in Medical Anthropology. Nueva York: Macmillian Publishing Co.

LESLIE, Charles M.

1977 "Pluralism and Integration in the Indian and Chinese Medical System", en: Landy, David (ed.), Culture, Disease and Healing. Studies in Medical Anthropology. Nueva York: Macmillian Publishing Co.

MARTÍNES MESANZA, Julio

s/f La medicina política (fotocopiado). 
MENÉNDEZ, E. L. y Di PARdo R. B.

$\mathrm{s} / \mathrm{f}$ "La representación social negativa de los procesos de salud/enfermedad/ atención en la prensa escrita", en Salud Colectiva, 2008, 4 (1), pp. 9-30.

MENÉNDEZ, Eduardo L.

1984 "Hacia una práctica médica alternativa. Hegemonía y autoatención (gestión)", en: Salud, Cuadernos de la Casa Chata 86/CIESAS, 1984.

1988 "Modelo Médico Hegemónico y Atención Primaria", Segundas Jornadas de Atención Primaria de la Salud. Buenos Aires, abril-mayo.

1998 "Estilos de vida, riesgos y construcción social. Conceptos similares y significados diferentes", en: Estudios Sociológicos de El Colegio de México, v. XVI, no. 46.

2000 "Factores culturales. De las definiciones a los usos específicos", en: E. Perdiguero y J. M. Comelles (ed). Medicina y cultura. Estudios entre la antropología y la medicina. Barcelona: ediciones Bellaterra.

2002 La parte negada de la cultura. Relativismo, diferencia y racismo. Barcelona: Ediciones Bellaterra.

2005a "Intencionalidad, experiencia y función: la articulación de los saberes médicos", en Revista de Antropología Social, año/vol. 014.

2005b "El Modelo Médico y la Salud de los Trabajadores", en Salud Colectiva, v. 9, no. 1, Lanús, enero-abril.

OTEGUI PASCUAL, Rosario,

"Factores socioculturales del dolor y el sufrimiento", en E. PERDiguero y J. M. Comelles (ed.). Medicina y cultura. Estudios entre la antropología y la medicina. Barcelona: ediciones Bellaterra. 